OPEN ACCESS

Edited by:

Salem Hannoun,

American University of

Beirut, Lebanon

Reviewed by:

Hirohisa Watanabe,

Fujita Health University, Japan

Ifrah Zawar,

Cleveland Clinic, United States

*Correspondence:

Michela Lupo

m.lupo@hsantalucia.it

tThese authors share first authorship

Specialty section:

This article was submitted to Applied Neuroimaging, a section of the journal

Frontiers in Neurology

Received: 11 November 2019

Accepted: 23 January 2020

Published: 25 February 2020

Citation:

Lupo M, Olivito G, Clausi S,

Siciliano L, Riso V, Bozzali M,

Santorelli FM, Silvestri G and Leggio M (2020) Cerebello-Cortical Alterations

Linked to Cognitive and Social

Problems in Patients With Spastic

Paraplegia Type 7: A Preliminary

Study. Front. Neurol. 11:82.

doi: 10.3389/fneur.2020.00082

\section{Cerebello-Cortical Alterations Linked to Cognitive and Social Problems in Patients With Spastic Paraplegia Type 7: A Preliminary Study}

\author{
Michela Lupo ${ }^{1 * 1}$, Giusy Olivito ${ }^{2,3+}$, Silvia Clausi ${ }^{1,2}$, Libera Siciliano ${ }^{2}$, Vittorio Riso ${ }^{4}$, \\ Marco Bozzali ${ }^{3,5}$, Filippo M. Santorelli ${ }^{6}$, Gabriella Silvestri ${ }^{4}$ and Maria Leggio ${ }^{1,2}$ \\ ${ }^{1}$ Ataxia Laboratory, IRCCS Fondazione Santa Lucia, Rome, Italy, ${ }^{2}$ Department of Psychology, Sapienza University of Rome, \\ Rome, Italy, ${ }^{3}$ IRCCS Fondazione Santa Lucia, Rome, Italy, ${ }^{4}$ Department of Neurology, IRCCS Fondazione Policlinico \\ Agostino Gemelli, Rome, Italy, ${ }^{5}$ Clinical Imaging Science Center, Brighton and Sussex Medical School, Brighton, \\ United Kingdom, ${ }^{6}$ Molecular Medicine, IRCCS Fondazione Stella Maris, Pisa, Italy
}

Spastic paraplegia type 7 (SPG7), which represents one of the most common forms of autosomal recessive spastic paraplegia (MIM\#607259), often manifests with a complicated phenotype, characterized by progressive spastic ataxia with evidence of cerebellar atrophy on brain MRI. Recent studies have documented the presence of peculiar dentate nucleus hyperintensities on T2-weighted images and frontal executive dysfunction in neuropsychological tests in SPG7 patients. Therefore, we decided to assess whether any particular MRI pattern might be specifically associated with SPG7 mutations and possibly correlated with patients' cognitive profiles. For this purpose, we evaluated six SPG7 patients, studying the cerebello-cortical network by MRI voxel-based morphometry and functional connectivity techniques, compared to 30 healthy control subjects. In parallel, we investigated the cognitive and social functioning of the SPG7 patients. Our results document specific cognitive alterations in language, verbal memory, and executive function in addition to an impairment of social task and emotional functions. The MRI scans showed a diffuse symmetric reduction in the cerebellar gray matter of the right lobule $\mathrm{V}$, right Crus I, and bilateral lobule VI, together with a cerebral gray matter reduction in the lingual gyrus, precuneus, thalamus, and superior frontal gyrus. The evidence of an over-connectivity pattern between both the right and left cerebellar dentate nuclei and specific cerebral regions (the lateral occipital cortex, precuneus, left supramarginal gyrus, and left superior parietal lobule) confirms the presence of cerebello-cortical dysregulation in different networks involved in cognition and social functioning in SPG7 patients.

Keywords: spastic paraplegia type 7, cerebellum, cognition, social skills, CCAS, functional connectivity, voxelbased morphometry 


\section{INTRODUCTION}

Mutations in the spastic paraplegia type 7 (SPG7) gene, encoding the mitochondrial protein paraplegin (MIM*602783), are responsible for a rare form of hereditary spastic paraplegia $(1,2)$ and are usually transmitted as an autosomal recessive trait, which can cause both pure and complex phenotypes (1). The most common clinical presentation of SPG7 is spasticataxia, which is often associated with optic atrophy, ptosis, and ophthalmoparesis, and brain MRI usually shows the presence of mild or moderate cerebellar atrophy (3-6).

Despite the fact that cerebellar degeneration is a hallmark of the SPG7 complex phenotype, to date, only a few studies have attempted to characterize the pattern of cerebellar involvement in correlation with other brain structures. In this regard, Hewamadduma et al. (7) proposed cerebellar vermis atrophy associated with an increase in the T2 signal on MRI images of the dentate nucleus (DN) as a possible specific MRI pattern in SPG7 (7). The DN alteration is of particular interest, given the cerebellar anatomy. Indeed, the $\mathrm{DN}$ is the major cerebellar output channel connecting to the cerebral cortex (8), and modifications in functional connectivity (FC) within specific cerebello-cortical networks have already been described in patients affected by other forms of cerebellar atrophy (9-12) and linked to motor, cognitive, and behavioral symptoms (13-22).

In addition to the recognized role in motor functions, many research studies have assessed an important role for the cerebellum in cognition, with a related specific cognitive pattern known as cerebellar cognitive affective syndrome (CCAS) or Schmahmann's syndrome. Interestingly, in addition to spastic ataxia, a peculiar cognitive/behavioral phenotype characterized by "emotional disconnection" has recently been described in an SPG7 patient (23).

On the basis of this evidence, we set up a preliminary study on the structural and functional cerebellar networks of six SPG7 patients to identify a potential MRI pattern underlying clinical alterations in specific cognitive and affective functions.

\section{MATERIALS AND METHODS}

\section{Participants}

Six adult male patients (mean age/SD $=46.33 / 12.93$ ) with spastic ataxia and diagnosis of SPG7 were recruited for this study by the Neurology Department of Fondazione Policlinico Gemelli, IRCCS. All of them showed cerebellar atrophy on their diagnostic brain MRI. The study protocol, including MRI acquisition and clinical and cognitive assessment of patients, was performed at the IRCCS Fondazione Santa Lucia. Confirmation of the presence of macroscopic cerebellar alterations on T2-weighted brain MRI scans was given by an expert neuro-radiologist and represented a major inclusion criterion. At the time of enrolment, none of the SPG7 patients presented with any current or past diagnosis of other neurological/psychiatric disorders. Cerebellar motor deficits were assessed using the International Cooperative Ataxia Rating Scale (ICARS) (24), which has a global score ranging from 0 (absence of any motor deficits) to 100 (presence of motor deficits at the highest degree). The patients' genetic, clinic, and demographic data are reported in Table 1. For the MRI analysis, 30 healthy subjects (HS), matched for age and sex (mean age $/ \mathrm{SD}=38.43 / 13.64 ; \mathrm{M} / \mathrm{F}=30 / 0)$, were recruited from the IRCCS Fondazione Santa Lucia as a control group. For the HS group, conventional MRI was inspected to exclude any pathological conditions according to the inclusion criteria.

The experimental protocol, designed according to the Helsinki Declaration, was approved by the Ethics Committee of the IRCCS Fondazione Santa Lucia. Written, informed consent was obtained from each subject per the Helsinki Declaration.

\section{Behavioral Assessments}

All patients underwent neuropsychological evaluation to investigate their cognitive profiles and social cognition abilities. Moreover, the Schmahmann's syndrome scale (SSS) was used (25) to evaluate the presence of cerebellar cognitive affective syndrome CCAS (15).

The neuropsychological assessment included the following tasks:

Intellectual level: Wechsler Adult Intelligence Scale (WAISIV) (26); Raven's Progressive Matrices '47 test (27).

Verbal Memory: immediate and delayed recall of prose memory (28); short- and long-term Rey's 15 words test (29); forward and backward digit span $(30,31)$.

Visuospatial Memory: Rey-Osterrieth Complex Figure Test (recall) (28); forward and backward Corsi (32).

Visuospatial abilities: Rey-Osterrieth Complex Figure Test (copy) (28).

Language: naming objects, naming verbs, and naming objects described by the examiner (33); generation of sentences (34).

Executive Functions: Stroop Test ("time effect" and "error effect”) (35); phonological fluency (36); verbal fluency (37); Wisconsin Card Sorting Test (WCST) (number of errors and perseverative errors) (38); Tower of London procedure (TOL) (39).

Attention: Multiple Features Target Cancellation task (40), and the Trail Making Test B-A (TMT B-A) (41).

To evaluate social cognition abilities, patients underwent the following tasks (see Appendix in Supplementary Material for details):

The Reading the Mind in the Eyes test (RME) $(42,43)$ was used to assess the first stage (automatic) of attributing relevant mental states to others regardless of the context.

The Emotion Attribution test (EA) $(44,45)$ was used to assess the ability to attribute emotions to others in a social context. The Theory of Mind (ToM) task (44-47) was used to assess the more advanced concepts of the ToM, such as double bluff, white lies, and persuasion.

\section{MRI Acquisition Protocol}

All patients and HSs underwent MRI examination at $3 \mathrm{~T}$ (Magnetom Allegra, Siemens, Erlangen, Germany) that included the following acquisitions: (1) dual-echo turbo spin-echo [TSE] $(\mathrm{TR}=6,190 \mathrm{~ms}, \mathrm{TE}=12 / 109 \mathrm{~ms}) ;$ (2) fast-FLAIR $(\mathrm{TR}=$ $8,170 \mathrm{~ms}, 204 \mathrm{TE}=96 \mathrm{~ms}$, TI $=2,100 \mathrm{~ms}$ ); (3) T1-weighted 3D 
TABLE 1 | Demographic, molecular, and clinical characteristics of SPG7 patients.

\begin{tabular}{|c|c|c|c|c|c|}
\hline Group & Age & $\begin{array}{l}\text { Age at } \\
\text { onset }\end{array}$ & Mutation & Protein & ICARS \\
\hline CB_1 & 54 & 25 & c.1779+1G > T + c.184_286del & $\begin{array}{l}\text { Splice site }+ \\
\text { Exon } 2 \text { deletion }\end{array}$ & 56 \\
\hline CB_2 & 53 & 45 & $\begin{array}{l}\text { c.1450-1del]_[c.1450_1457del] + } \\
\text { c.1931C>A }\end{array}$ & $\begin{array}{l}\text { Splice site + } \\
\text { p.Thr644Asn }\end{array}$ & 27 \\
\hline CB_3 & 55 & 45 & c.637 C>T/- & p.Arg213*/- & 9 \\
\hline CB_4 & 54 & 43 & c. $637 \mathrm{C}>\mathrm{T}+\mathrm{c} .1529 \mathrm{C}>\mathrm{T}$ & $\begin{array}{l}\text { p.Arg213* + } \\
\text { p.Ala510Val }\end{array}$ & 35 \\
\hline CB_5 & 23 & C & c. $1013 \mathrm{G}>\mathrm{T} /-$ & p.Gly338Val/- & 17 \\
\hline CB_6 & 39 & A & c. $1369 \mathrm{C}>\mathrm{T}+$ c. $1617 \mathrm{delC}$ & p. Arg457* + p.Val540CfsX52 & 7 \\
\hline $\begin{array}{l}\text { Mean } \\
\text { (sd) }\end{array}$ & $\begin{array}{c}46.33 \\
(12.93)\end{array}$ & $\begin{array}{c}35.33 \\
(10.86)\end{array}$ & - & - & $\begin{array}{l}25.17 \\
(18.49)\end{array}$ \\
\hline
\end{tabular}

$S D$, standard deviations; $C$, childhood; $A$, adolescence.

high-resolution scan (3D modified driven equilibrium Fourier transform $(\mathrm{MDEFT})(\mathrm{TR}=1,338 \mathrm{~ms}, \mathrm{TE}=2.4 \mathrm{~ms}$, matrix $=256$ $\times 224 \times 176$, in-plane FOV $=250 \times 250 \mathrm{~mm}^{2}$, slice thickness $=$ $1 \mathrm{~mm}$ ); (4) T2*-weighted echo-planar imaging (EPI) sensitized to blood oxygenation-level dependent imaging (BOLD) contrast ( $\mathrm{TR}=2,080 \mathrm{~ms}, \mathrm{TE}=30 \mathrm{~ms}, 32$ axial slices parallel to the AC-PC line, matrix $64 \times 64$, pixel size $3 \times 3 \mathrm{~mm}^{2}$, slice thickness $2.5 \mathrm{~mm}$, flip angle $70^{\circ}$ ) for resting-state fMRI. BOLD echo-planar images were collected during rest for a $7 \mathrm{~min}$ and $20 \mathrm{~s}$ period, resulting in a total of 220 volumes. During this acquisition, subjects were instructed to keep their eyes closed, not to think of anything in particular, and not to fall asleep.

\section{Statistical Analysis \\ Behavioral Assessments}

To evaluate the general neuropsychological and social cognition profiles, the raw scores obtained in each task were corrected for age and educational values according to the corresponding published normative data.

\section{Image Processing and Data Analysis}

An independent two-sample T-test ensured that SPG7 patients and HS did not differ in terms of age $(t=-1.30, p<0.05)$.

\section{Cerebellar Gray Matter Analysis}

Voxel-based morphometry (VBM) was used to identify differences in regional cerebellar volume between SPG7 and HS. The cerebellum was pre-processed individually using the Spatially Unbiased Infratentorial Template (SUIT) toolbox (48) implemented in Statistical Parametric Mapping version 8 [Wellcome Department of Imaging Neuroscience; SPM-8 (http://www.fil.ion.ucl.ac.uk/spm/)]. The procedure involved is as follows: cropping and isolating the cerebellum from the T1 anatomical images, normalizing each cropped image into SUIT space, and reslicing the probabilistic cerebellar atlas into individual subject spaces using the deformation parameters from normalization. The modulated gray matter (GM) probability maps were finally smoothed using an 8-mm FWHM Gaussian kernel, and statistical analyses were performed on the resulting
GM maps with a voxel-wise two-sample t-test analysis for assessments of between-group differences in regional GM cerebellar volumes. The results were considered significant at $P$ $<0.05$ after FWE cluster-level correction (clusters formed with $P<0.005$ at the uncorrected level).

\section{Whole-Brain Gray Matter Analysis}

To control for the effect of the accompanying cortical atrophy in SPG7 patients, whole-brain VBM was also performed. MDEFT T1 volumes were segmented into gray GM maps and registered to the Montreal Neurological Institute (MNI) space by means of the "New Segment" and "DARTEL" routines in SPM8 (http://www. fil.ion.ucl.ac.uk/spm/, Wellcome Trust Center for Neuroimaging, Institute of Neurology, University College London, UK) (49). VBM statistical analysis was performed to compare the GM maps between the patients and HS, entered as independent groups. The analysis excluded voxels in the cerebellum and was restricted to the cerebrum, which was entered as an explicit mask. For this analysis, intracranial volume was set as a covariate of no interest. $\mathrm{T}$-contrasts were evaluated with voxel significance set at $p<0,001$ and corrected for family-wise error (FWE) at the cluster level with the significance level set at $p<0.05$.

\section{Resting-State fMRI Data Pre-processing}

fMRI data were pre-processed using SPM8 (http://www.fil.ion. ucl.ac.uk/spm/) and in-house software implemented in Matlab (The Mathworks Inc., Natick, MA, USA). For each subject, the first four volumes of the fMRI series were discarded to allow for T1 equilibration effects. The pre-processing steps included correction for head motion, compensation for slicedependent time shifts, normalization to the EPI template in MNI coordinates provided with SPM8 and smoothing with a 3D Gaussian kernel with $8 \mathrm{~mm}^{3}$ full-width-at-half-maximum. For each data set, motion correction was checked to ensure that the maximum absolute shift did not exceed $2 \mathrm{~mm}$ and the maximum absolute rotation did not exceed $1.5^{\circ}$. Global temporal drift was removed using a third-order polynomial fit, the signal was regressed against the realignment parameters, and the signal was averaged over whole brain voxels to remove 
other potential sources of bias. All images were then filtered by a phase-insensitive band-pass filter (pass band $0.01-0.08 \mathrm{~Hz}$ ) to reduce the effect of low-frequency drift and high-frequency physiological noise. Considering that GM atrophy may affect FC (50), every participant's total GM volume (absolute value) was also calculated and set as a nuisance variable for this analysis.

\section{Definition of Regions of Interest and Seed-Based Analyses}

The cerebellar DNs were chosen as regions of interest (ROIs) to test cerebello-cerebral FC differences in patients compared to controls. The choice of the DNs as ROIs was linked both to their role as the major cerebellar output channels to the cerebral cortex and to the DN alteration on MRI T2 sequences described in SPG7 patients (7). Left and right DN masks were separately extracted according to the SUIT atlas (48) and resliced in EPI standard space. A first-level SPM model was used to estimate the correlation between each voxel in the brain and the seed regions. The mean time course within each seed region of interest was extracted for every participant and used as a regressor in a firstlevel SPM analysis. The resulting beta images are thus equivalent to the Fisher z-transformed maps of the correlation coefficient. These images were taken to the second level for group analysis. At the second level, the group-level main effect of seed-to-voxel connectivity was tested by means of the F-test of significance for both left and right DNs. A two-sample $t$-test model was then used to explore differences in connectivity between patients and controls in each ROI. Between-group statistical significance was set at $p<0.05$, FWE-corrected at the cluster level (clusters formed with uncorrected voxels; $p<0.005$ at the voxel level).

\section{RESULTS}

\section{Behavioral Assessments}

The scores of the performances obtained by SPG7 patients in the neuropsychological evaluation are reported in Supplementary Table 1 . The assessments revealed the presence of CCAS according to the pathological scores obtained in at least three out of 10 subtests of the SSS. Moreover, the SPG7 group returned pathological results in specific verbal, language, and executive tasks of the neuropsychological assessment; specifically, $66 \%$ of SPG7 patients (four subjects) failed in both immediate and delayed recall of prose memory, naming objects described by the examiner, and phonological fluency; moreover, $83 \%$ of patients (five subjects) had problems in the naming verbs task and a poor time score in the Stroop task. Additionally, three patients had problems in the naming objects task, the long-term Rey's 15 words test, and the Rey-Osterrieth Figure (copy condition) (see Supplementary Table 1).

Regarding social cognition evaluation, the SPG7 group return pathological results in the ToM (66\% of SPG7 patients), the RME total scores ( $83 \%$ of patients), and the "embarrassed" emotion of the EA test (100\% of patients), while no differences compared to normative data were observed in the other emotions (see Supplementary Table 2).

\section{MRI Analysis}

No subject was excluded due to motion artifacts in the MRI scans.

\section{Cerebellar VBM}

Voxel-wise analysis of the cerebellar GM, comparing the SPG7 patients vs. HS, revealed a specific pattern of GM atrophy in the cerebellar cortex of SPG7 patients; indeed, VBM showed a large cluster of significantly decreased GM volume involving the right lobule V and bilateral lobule VI with extension in the right Crus I. No regions of increased cerebellar GM volume compared to HS were found in SPG7 patients. Detailed statistics and peak voxels showing the greatest significant difference in the cluster are reported in Table $\mathbf{2 A}$. The results of cerebellar VBM are shown in Figure 1A.

\section{Cerebral VBM}

Voxel-wise analysis of the cerebral GM maps revealed a significant pattern of GM atrophy in the cerebral cortex of SPG7 patients compared to controls. More specifically, the VBM analysis showed different clusters of significantly decreased GM volume involving cortical and subcortical regions in the left and right cerebral hemispheres, such as the bilateral lingual gyrus, the bilateral thalamus, the right precuneus and cingulate gyrus, and the left superior frontal gyrus and frontal pole. Detailed statistics and peak voxels showing the greatest significant differences in the clusters are reported in Table 2B. The results of cerebral voxel-based morphometry are shown in Figure 1B.

\section{Seed-Based Analysis of Dentate-Cerebral Functional Connectivity}

The left and right DN masks used as ROIs for the FC analysis are shown in Figure 2A. The seed-based analysis revealed significant FC alterations in SPG7 patients vs. HS: specifically, a significant cluster of increased FC was found between the left DN and ipsilateral cerebral regions, including the lateral occipital cortex, the supramarginal gyrus, and the superior parietal lobule (Figure 2B). Similarly, a significant cluster of increased FC was found between the right DN and ipsilateral cerebral regions, including the lateral occipital cortex and the precuneus (Figure 2C). No regions of significantly decreased FC with the left and right DNs were found. Detailed statistics and peak voxels showing the greatest significant difference in the clusters are reported in Supplementary Table 3.

\section{DISCUSSION}

The present preliminary study provides the first evidence of specific cerebellar modifications that affect long-distance regions of the brain in a cohort of SPG7 patients, showing a link between the anatomical alterations and the clinical symptoms found in terms of cognitive and social ability impairments.

Our cohort of SPG7 patients, all of whom showed signs of cerebellar atrophy on the diagnostic brain MRI, was assessed by means of high-resolution brain MRI techniques, in parallel with neuropsychological and social tasks for scoring the patients' cognitive and emotional performances. 
TABLE 2 | Statistics of cerebellar (A) and cerebral (B) GM differences (SPG7 < HS).

\begin{tabular}{|c|c|c|c|c|c|c|}
\hline & $\begin{array}{l}\text { Cluster size } \\
\text { (NoV) }\end{array}$ & & $\begin{array}{c}\text { Coordinates } \\
x y z\end{array}$ & & Cluster peak Z-score & Cerebellar regions \\
\hline \multirow[t]{3}{*}{ (A) } & 31665 & 16 & -48 & -11 & 3.84 & R-Lobule V \\
\hline & & 21 & -40 & -17 & 3.69 & R-Lobule VI \\
\hline & & -23 & -58 & -14 & 3.62 & L-Lobule VI \\
\hline \multicolumn{7}{|c|}{ Cerebral regions } \\
\hline \multirow[t]{11}{*}{ (B) } & 1229 & 9 & -63 & -6 & 5.15 & R-Lingual Gyrus \\
\hline & & -21 & -64 & -9 & 4.96 & L-Lingual Gyrus \\
\hline & & -8 & -66 & -6 & 4.91 & \\
\hline & 603 & 2 & -67 & 42 & 4.66 & R-Precuneus \\
\hline & & 6 & -55 & 22 & 4.20 & \\
\hline & 760 & 9 & -15 & 15 & 4.65 & R-Thalamus \\
\hline & & -9 & -18 & 12 & 4.13 & L-Thalamus \\
\hline & & -6 & -21 & 1 & 3.89 & \\
\hline & 588 & -4 & 29 & 57 & 4.18 & L-Superior Frontal Gyrus \\
\hline & & -4 & 44 & 39 & 3.87 & \\
\hline & & -15 & 30 & 57 & 3.65 & \\
\hline
\end{tabular}

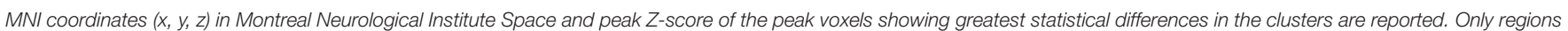
that survived after correction for multiple comparisons (FWE corrected $p<0.05$ ) have been considered. NoV, number of voxels; $L$, left; $R$, right.

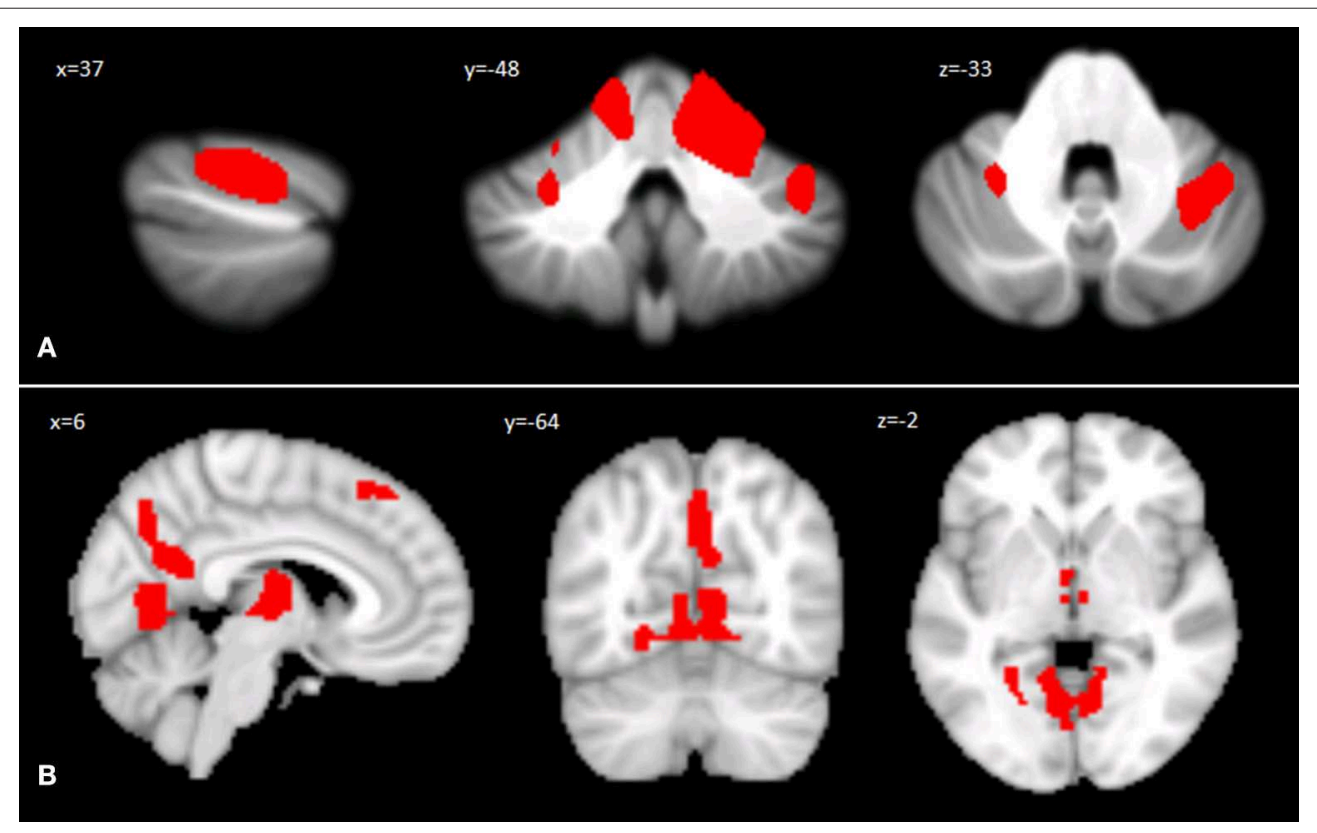

FIGURE 1 | (A) Between-group voxel-based comparison of cerebellar GM volumes. Cerebellar regions showing patterns of significantly reduced GM in SPG7 compared to HS are reported and superimposed on sagittal $(x=37)$, coronal $(y=-48)$, and axial $(z=-33)$ sections of the Spatially Unbiased Infratentorial Template (SUIT; 41). Statistical significance was found at the cluster level (FWE =0.05; cluster size: 31665), with peak voxels centered in the right lobule $\mathrm{V}$ and bilateral lobule $\mathrm{VI}$ with extension in the right Crus I. Images are shown according to neurological conventions. (B) Between-group voxel-based comparison of cerebral GM volumes. Cerebral regions showing patterns of significantly reduced GM compared to HS in SPG7 patients are reported in sagittal $(x=6)$, coronal $(y=-64)$, and axial $(z=-2)$ coordinates in Montreal Neurological Institute space. Left and right hemispheres are according to neurological conventions. See Tables $2 \mathbf{A}$,B for detailed statistics.

In agreement with previous data obtained in patients with various cerebellar pathologies $(11,16,51-56)$, the results of the neuropsychological assessments indicated the presence of CCAS and serious impairments in specific verbal, language, and executive tasks in our SPG7 cohort.
Additionally, the in-depth investigation of social skills indicated specific difficulties in the attribution of the "embarrassed" emotion, in the automatic attribution of relevant mental states regardless of the context (RME), and in theory of mind. Interestingly, a recent study by Clausi et al. (9) 


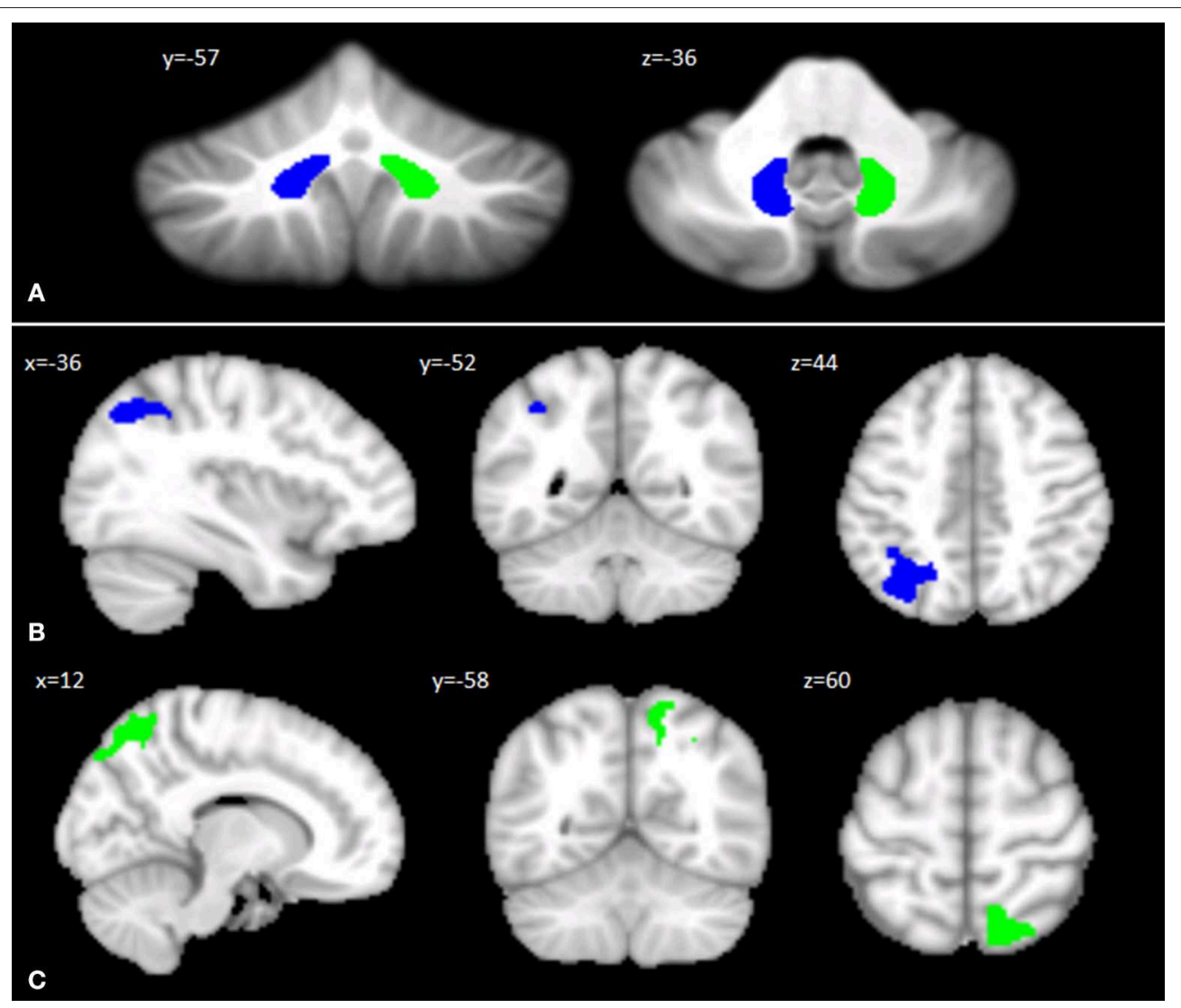

FIGURE 2 | (A) Seed regions in the cerebellar dentate nuclei. Coronal (y) and axial (z) views of the generated left (blue) and right (green) dentate nuclei used as regions of interest for assessing cerebello-cerebral FC. The left and right cerebellar DNs are superimposed on the Spatially Unbiased Infratentorial Template of the cerebellum and brainstem (SUIT, 41). (B,C) Patterns of DN functional connectivity with the cerebral cortex. Patterns of increased dentate-cerebral FC are shown for the left (B) and right (C) DN in different colors (blue and green, respectively). Sagittal (x), coronal (y), and axial slices (z) in Montreal Neurological Institute space. Clusters of increased dentate-cerebral FC were considered significant after correction for multiple comparisons (FWE corrected $p<0.05$ ). Images are shown according to neurological conventions. See Supplementary Table 3 for detailed statistics.

described a similar impairment in patients affected by cerebellar atrophy. Indeed, they were characterized by a lack of ability to "tune in" to the mental state of another person both at an unconscious and an automatic level, as assessed by RME, and at a more complex and conscious level, as assessed by ToM. In the same way, the low score specifically obtained in the "embarrassed" emotion is consistent with the high level of social interaction implied by this complex emotion (57). Altogether, our results not only confirm executive dysfunctions and impairment in facial emotional expressions, already described in a single SPG7 case $(23,58)$, but also allow us to delineate a multifaceted cognitive and social profile as part of the SPG7 complex phenotype.

Importantly, the neuroimaging studies suggested the association of characteristic structural brain alterations with such cognitive/emotional features, as cerebellar VBM showed GM reduction in the right lobule $\mathrm{V}$ and Crus I and the bilateral lobule VI. Interestingly, while the anterior lobule $\mathrm{V}$ is more involved in somatosensory and motor aspects, both the posterolateral cerebellum lobule VI and Crus I are associated with the processing of cognitive and emotional information $(21,59)$, and Crus $\mathrm{I}$ is also involved in the mentalizing network of social abilities (60). Furthermore, cerebral VBM indicated GM reduction in the lingual gyrus, precuneus, thalamus, and superior frontal gyrus. It must be noted that the lingual gyrus plays a role in the identification and recognition of words, while the precuneus and superior frontal gyrus are involved in different aspects of social interactions and are included in the default mode network (DMN) (61-65).

Thus, in view of these data, the verbal memory and language impairment shown by our SPG7 patients might be related to the atrophy in the cerebellar posterior lobules and in the lingual gyrus, while the "theory of mind" alterations might be linked to the atrophy in the precuneus and superior frontal gyrus, supporting the relevance of the functional alteration of cerebellocerebral networks implicated in different cognitive and social functions $(10,12,66)$.

In this regard, our functional connectivity results support this hypothesis. Indeed, an abnormal pattern of FC was found between both the right and left DNs and specific cortical areas 
in our SPG7 patients, characterized by an increased FC of the right $\mathrm{DN}$ with ipsilateral regions of the lateral occipital cortex, known to be involved in somatosensory processing, and the precuneus, which is part of the DMN and is involved in social cognition ability. The left DN showed an increased FC with the ipsilateral occipital cortex, the left supramarginal gyrus, and the left superior parietal lobule. In particular, the supramarginal gyrus is involved not only in retrieval and episodic memory but also in social interaction, similar to the left superior parietal lobe (61-65), confirming the cerebello-cortical dysregulation in different networks involved in social functioning $(9,12,61,64)$.

We hypothesize that hyperconnectivity is the pathological manifestation of altered functional interaction between the $\mathrm{DN}$ and cerebral regions. This dysregulation is conceivable considering cerebellar cortical degeneration. Indeed, as a result of the degenerative process, the increased FC evidenced in the present study suggests a release of the inhibitory control that is normally exerted by the cerebellar cortex on the DNs. As a consequence, the DNs increase their excitatory outputs to the cerebral cortex, thus resulting in a pattern of overconnectivity that impairs the optimization of functions in the dentate-thalamo-cortical tract subserving cognitive and social functioning $(12,67)$.

\section{CONCLUSION}

This study reported a preliminary characterization of the cognitive and emotional profile of the SPG7 complex phenotype, which might be explained by cerebellar and cortical structural alterations and the functional dysregulation of specific cerebellocortical networks.

Moreover, in the current study, the cerebello-cortical overconnectivity results were strictly ipsilateral, in agreement with previous studies showing a similar altered connection pattern between the cerebellum and cerebral cortex $(8,11,68,69)$. In this regard, we emphasize that although the majority of cerebello-cerebral anatomical connections are known to be contralateral (70), functional connectivity can be independent from the underlying structural (anatomical) connectivity (71) since FC typically refers to the neural synchronization between separated brain regions (72).

Overall, it is important to note that the combined use of structural and functional connectivity investigations has been fundamental to characterizing, for the first time, the anatomical specificity of SPG7 pathology.

The major limitation of this study is the small sample of SPG7 patients, which is a product of the rarity of this neurogenetic condition, and the presence of only male subjects. Moreover, considering that the cluster-extent based threshold should be

\section{REFERENCES}

1. Casari G, De Fusco M, Ciarmatori S, Zeviani M, Mora M, Fernandez P, et al. Spastic paraplegia and OXPHOS impairment caused by mutations in ideally set at 0.001 (73), another limitation to consider is that FC cerebellar VBM and FC analysis gave significant results only when using a more permissive $p$ threshold $(0,005)$.

In spite of these limitations, the present results give a preliminary profile of the general cognitive and social alterations associated with this pathology. Hopefully, these issues will be addressed in future studies including larger SPG7 cohorts.

\section{DATA AVAILABILITY STATEMENT}

The raw data supporting the conclusions of this article will be made available by the authors, without undue reservation, to any qualified researcher.

\section{ETHICS STATEMENT}

The studies involving human participants were reviewed and approved by Ethics Committee of the IRCCS Fondazione Santa Lucia. The patients/participants provided their written informed consent to participate in this study.

\section{AUTHOR CONTRIBUTIONS}

ML drafting and revising the manuscript, study concept and design, and analysis and interpretation of data. Accepts responsibility for conducting the research and for final approval, acquisition of data, and study supervision. GO drafting and revising the manuscript, study concept, acquisition, and analysis of MRI data. SC and LS drafting and revising the manuscript and acquisition of data. VR revising the manuscript and acquisition of molecular diagnosis. MB supervision of MRI analysis and revising the manuscript. FS supervision of molecular diagnosis analysis and revising the manuscript. GS enrolment of patients, supervision of molecular diagnosis analysis, and revising the manuscript. ML drafting and revising the manuscript, study concept and design, analysis and interpretation of data, and accepts responsibility for conducting research and for final approval and study supervision.

\section{ACKNOWLEDGMENTS}

The editing support of American Journal Experts is acknowledged.

\section{SUPPLEMENTARY MATERIAL}

The Supplementary Material for this article can be found online at: https://www.frontiersin.org/articles/10.3389/fneur. 2020.00082/full\#supplementary-material paraplegin, a nuclear encoded mitochondrial metalloprotease. Cell. (1998) 93:973-83. doi: 10.1016/S0092-8674(00)81203-9

2. Wilkinson PA, Crosby AH, Turner C, Bradley, Ginsberg LJ, Wood NW, et al. A clinical, genetic and biochemical study of SPG7 mutations in 
hereditary spastic paraplegia. Brain. (2004) 127:973-80. doi: 10.1093/brain/ awh 125

3. Elleuch N, Depienne C, Benomar A, Hernandez AM, Ferrer X, Fontaine B, et al. Mutation analysis of the paraplegin gene (SPG7) in patients with hereditary spastic paraplegia. Neurology. (2006) 66:654-9. doi: 10.1212/01.wnl.0000201185.91110.15

4. Brugman F, Scheffer H, Wokke JH, Nillesen WM, de Visser M, Aronica E, et al. Paraplegin mutations in sporadic adult-onset upper motor neuron syndromes. Neurology. (2008) 71:1500-5. doi: 10.1212/01.wnl.0000319700.11606.21

5. Tzoulis C, Denora PS, Santorelli FM, Bindoff LA. Hereditary spastic paraplegia caused by the novel mutation 1047insC in the SPG7 gene. J Neurol. (2008) 255: 1142-4. doi: 10.1007/s00415-008-0858-y

6. Klebe S, Depienne C, Gerber S, Challe G, Anheim M, Charles P, et al. Spastic paraplegia gene 7 in patients with spasticity and/or optic neuropathy. Brain. (2012) 135:2980-93. doi: 10.1093/brain/aws240

7. Hewamadduma CA, Hoggard N, O'Malley R, Robinson MK, Beauchamp NJ, Segamogaite R, et al. Novel genotype-phenotype and MRI correlations in a large cohort of patients with SPG7 mutations. Neurol Genet. (2018) 4:e279. doi: 10.1212/NXG.0000000000000279

8. Middleton FA, Strick PL. Basal ganglia and cerebellar loops: motor and cognitive circuits. Brain Res Brain Res Rev. (2000) 31:236-50. doi: 10.1016/S0165-0173(99)00040-5

9. Clausi S, Lupo M, Olivito G, Siciliano L, Contento MP, Aloise F, et al. Depression disorder in patients with cerebellar damage: awareness of the mood state. J Affect Disord. (2019) 245:386-93. doi: 10.1016/j.jad.2018.11.029

10. Olivito G, Lupo M, Iacobacci C, Clausi S, Romano S, Masciullo $\mathrm{M}$, et al. Microstructural MRI basis of the cognitive functions in patients with Spinocerebellar ataxia type 2. Neuroscience. (2017) 366,44-53. doi: 10.1016/j.neuroscience.2017.10.007

11. Lupo M, Siciliano L, Olivito G, Masciullo M, Bozzali M, Molinari M, et al. Non-linear spelling in writing after a pure cerebellar lesion. Neuropsychologia. (2019) 132:107143. doi: 10.1016/j.neuropsychologia.2019.107143

12. Olivito G, Clausi S, Laghi F, Tedesco AM, Baiocco R, Mastropasqua C, et al. Resting-state functional connectivity changes between dentate nucleus and cortical social brain regions in autism spectrum disorders. Cerebellum. (2017) 16:283-92. doi: 10.1007/s12311-016-0795-8

13. Schmahmann JD. An emerging concept. The cerebellar contribution to higher function. Arch Neurol. (1991) 48:1178-87. doi: 10.1001/archneur.1991.00530230086029

14. Schmahmann JD, Pandya DN. The cerebrocerebellar system. IntRev Neurobiol. (1997) 41:31-60. doi: 10.1016/S0074-7742(08)6 0346-3

15. Schmahmann JD, Sherman JC. The cerebellar cognitive affective syndrome. Brain. (1998) 121:561-79. doi: 10.1093/brain/121.4.561

16. Tedesco AM, Chiricozzi FR, Clausi S, Lupo M, Molinari M, Leggio MG. The cerebellar cognitive profile. Brain. (2011). 134:3672-86. doi: 10.1093/brain/awr266

17. Lupo M, Troisi E, Chiricozzi FR, Clausi S, Molinari M, Leggio M. Inability to process negative emotions in cerebellar damage: a functional transcranial doppler sonographic study. Cerebellum. (2015) 14:663-9. doi: 10.1007/s12311-015-0662-z

18. Clausi S, Iacobacci C, Lupo M, Olivito G, Molinari M, Leggio M. The role of the cerebellum in unconscious and conscious processing of emotions: a review. Appl Sci. (2017) 7:521. doi: 10.3390/app7050521

19. Clausi S, Olivito G, Lupo M, Siciliano L, Bozzali M, Leggio M. The cerebellar predictions for social interactions: theory of mind abilities in patients with degenerative cerebellar atrophy. Front Cell Neurosci. (2018) 12:510. doi: $10.3389 /$ fncel.2018.00510

20. Lupo M, Olivito G, Iacobacci C, Clausi S, Romano S, Masciullo M, et al. The cerebellar topography of attention sub-components in spinocerebellar ataxia type 2. Cortex. (2018) 108:35-49. doi: 10.1016/j.cortex.2018.07.011

21. Schmahmann JD. The role of the cerebellum in cognition and emotion:personal reflections since 1982 on the dysmetria of thought hypothesis, and its historical evolution from theory to therapy. Neuropsychol Rev. (2010) 20:236-60. doi: 10.1007/s11065-010-9142-x

22. Schmahmann JD. The cerebellum and cognition. Neurosci Lett. (2018) 688:62-75. doi: 10.1016/j.neulet.2018.07.005
23. Zhang L, McFarland KN, Subramony SH, Heilman KM, Ashizawa T. SPG7 and impaired emotional communication. Cerebellum. (2017) 16:595-8. doi: 10.1007/s12311-016-0818-5

24. Trouillas P, Takayanagi T, Hallett M, Currier RD, Subramony SH, Wessel $\mathrm{K}$, et al. International Cooperative Ataxia Rating Scale for pharmacological assessment of the cerebellar syndrome. The Ataxia Neuropharmacology Committee of the World Federation of Neurology. J Neurol Sci. (1997) 145:205-11. doi: 10.1016/S0022-510X(96)00231-6

25. Hoche F, Guell X, Vangel MG, Sherman JC, Schmahmann JD. The cerebellar cognitive affective/Schmahmann syndrome scale. Brain. (2018) 141:248-70. doi: 10.1093/brain/awx317

26. Wechsler D. Wechsler Adult Intelligence Scale. 4th ed. San Antonio, TX: Pearson Assessment (2008). doi: 10.1037/t15169-000

27. Raven JC. Progressive Matrices. Sets A, Ab, B: Board and Book Forms. London: Lewis (1949).

28. Carlesimo GA, Buccione I, Fadda L, Graceffa A, Mauri M, Lorusso S, et al. Standardizzazione di due test di memoria per uso clinico: breve racconto e figura di rey. Nuova Rivista Neurol. (2002) 1:1-13.

29. Rey A. Memorisation d'une sèrie de 15 mots en 5 rèpètions. In: Rey A, editor. L'examen clinique en psychologie. Paris: Presses Universiteries de France (1958).

30. Wechsler D. A standardized memory scale for clinical use. J Psychol. (1945) 87-95. doi: 10.1080/00223980.1945.9917223

31. Orsini A, Grossi D, Capitani E, Laiacona M, Papagno C, Vallar G. Verbal and spatial immediate memory span: normative data from 1,355 adults and 1,112 children. Italian J Neurol Sci. (1987) 8:539-48. doi: 10.1007/BF02333660

32. Corsi PM. Human memory and the medial temporal regions of the brain. Dissertat Abstr Int. (1972) 34:891B.

33. Miceli G, Laudanna A, Burani C, Capasso R. Batteria per l'Analisi dei Deficit Afasici (BADA). Roma: CEPSAG (1994).

34. Spinnler H, Tognoni G. Standardizzazione e taratura italiana di test neuropsicologici: gruppo italiano per lo studio neuropsicologico dellinvecchiamento Italian journal of neurological sciences. Milano: Masson Italia Periodici (1987).

35. Caffarra P, Vezzadini G, Dieci F, Zonato F, Venneri A. Rey-Osterrieth complex figure: normative values in an Italian population sample. Neurol Sci. (2002) 22:443-7. doi: $10.1007 / \mathrm{s} 100720200003$

36. Borkowsky JG, Benton AL, Spreen O. Word fluency and brain-damage. Neuropsychologia. (1967) 5:135-40. doi: 10.1016/0028-3932(67)90015-2

37. Woods SP, Scott JC, Sires DA, Grant I, Heaton RK, Tröster AI. HIV Neurobehavioral Research Center Group. Action (verb) fluency: test-retest reliability, normative standards, and construct validity. J Int Neuropsychol Soc. (2005) 11:408-15. doi: 10.1017/S1355617705050460

38. Heaton RK, Chelune GJ, Talley JL, Kay GG, Curtiss G. WCST: wisconsin card sorting test. Forma completa revisionata. In: Hardoy MC, Carta MG, Hardoy MJ, Cabras PL, editors. Firenze: It. O.S. Organizzazioni Speciali (2000).

39. Krikorian R, Bartok J, Gay N. Tower of London procedure: a standard method and developmental data. J Clin Exp Neuropsychol. (1994) 16:840-50. doi: $10.1080 / 01688639408402697$

40. Gainotti G, Marra C, Villa G. A double dissociation between accuracy and time of execution on attentional tasks in Alzheimer's disease and multi-infarct Dementia. Brain. (2001) 124:731-8. doi: 10.1093/brain/124.4.731

41. Giovagnoli AR, Del Pesce M, Mascheroni S, Simoncelli M, Laiacona M, Capitani E. Trail making test: normative values from 287 normal adult controls. Ital J Neurol Sci. (1996) 17:305-9. doi: 10.1007/BF01997792

42. Baron-Cohen S, Wheekwright S, Hill J, Raste Y, Plumb I. The "Reading the mind in the eyes" test revised version: a study with normal adults, and adults with asperger syndrome or high-functioning autism. J Child Psychol Psych. (2001) 42:241-51. doi: 10.1111/1469-7610.00715

43. Serafin M, Surian L. Il test degli Occhi: uno strumento per valutare la "teoria della mente." Giornale Italiano di Psicol. (2004) 31:213-36. Available online at: http://hdl.handle.net/11572/73819

44. Prior M, Marchi S, Sartori G. Cognizione Sociale e Comportamento. Vol. 1, Uno Strumento Per la Misurazione. Padova: Upsel Domenghini Editore (2003).

45. Blair RJ, Cipolotti L. Impaired social response reversal. A case of "acquired sociopathy." Brain. (2000) 123:1122-41. doi: 10.1093/brain/123.6.1122

46. Happè FGE. An advanced text of theory of mind: understanding of story characters' thoughts and feelings by able autistic, mentally handicapped 
and normal children and adults. J Autism Dev Disord. (1994) 24:129-54. doi: 10.1007/BF02172093

47. van Harskamp NJ, Rudge P, Cipolotti L. Cognitive and social impairments in patients with superficial siderosis. Brain. (2005) 128:1082-92. doi: 10.1093/brain/awh487

48. Diedrichsen J, Balsters JH, Flavell J, Cussans E, Ramnani N. A probabilistic MR atlas of the human cerebellum. Neuroimage. (2009) 46:39-46. doi: 10.1016/j.neuroimage.2009.01.045

49. Ashburner J, Csernansky JG, Davatzikos C, Fox NC, Frisoni GB, Thomson PM. Computer-assisted imaging to assess brain structure in healthy and diseased brains. Lancet Neurol. (2003) 2:79-88. doi: 10.1016/S1474-4422(03)00304-1

50. De Vico Fallani F, Richiardi J, Chavez M, Achard S. Graph analysis of functional brain networks: practical issues in translational neuroscience. Philos Trans R Soc Lond B Biol Sci. (2014) 369:1653. doi: 10.1098/rstb.2013.0521

51. Gambardella A, Annesi G, Bono F, Spadafora P, Valentino P, Pasqua AA, et al. CAG repeat lenght and clinical features in three Italian families with spinocerebellar ataxia type 2 (SCA2): early impairment of Wisconsin Card Sorting Test and saccade velocity. J Neurol. (1998) 245:647-52. doi: 10.1007/s004150050261

52. Le Pira F, Zappalà, G., Saponara R, Domina E, Restivo D, Reggio E, et al. Cognitive findings in spinocerebellar ataxia type 2: relationship to genetic and clinical variables. J Neurol Sci. (2002) 201:53-57. doi: 10.1016/S0022-510X(02)00194-6

53. Kawai Y, Suenaga M, Watanabe H, Sobue G. Cognitive impairment in spinocerebellar degeneration. Eur Neurol. (2009) 61:257-68. doi: $10.1159 / 000206850$

54. Sokolovsky N, Cook A, Hunt H, Giunti P, Cipolotti L. A preliminary characterization of cognition and social cognition in spinocerebellar ataxia types 2, 1, and 7. Behav Neurol. (2010) 23:17-29. doi: 10.1155/2010/395045

55. Mercadillo RE, Galvez V, Diaz R, Hernàndez-Castillo CR, Campos-Romo A, Boll MC, et al. Parahippocampal gray matter alterations in spinocerebellar ataxia type 2 identified by voxel based morphometry. J Neurol Sci. (2014) 347:50-8. doi: 10.1016/j.jns.2014.09.018

56. Lieto M, Riso V, Galatolo D, De Michele G, Rossi S, Barghigiani M, et al. The complex phenotype of spinocerebellar ataxia type 48 (SCA48) in eight unrelated Italian families. Eur J Neurol. (2020) 27:498-505. doi: 10.1111/ene.14094

57. Tangney JP, Stuewig J, Mashek DJ. Moral emotions and moral behavior. Ann Rev Psychol. (2007) 58:345-72. doi: 10.1146/annurev.psych.56.091103.0 70145

58. Heilman KM, Leon SA, Burtis DB, Ashizawa T, Subramony SH. Affective communication deficits associated with cerebellar degeneration. Neurocase. (2014) 1:18-26. doi: 10.1080/13554794.2012.713496

59. Stoodley CJ, Schmahmann JD. Evidence for topographic organization in the cerebellum of motor control versus cognitive and affective processing. Cortex. (2010) 46:831-44. doi: 10.1016/j.cortex.2009.11.008

60. Sokolov AA, Miall RC, Ivry RB. The cerebellum: adaptive prediction for movement and cognition. Trends Cogn Sci. (2017) 21:313-32. doi: 10.1016/j.tics.2017.02.005

61. Habas C, Kamdar N, Nguyen D, Prater K, Beckmann CF, Menon V, et al. Distinct cerebellar contributions to intrinsic connectivity networks. $J$ Neurosci. (2009) 29:8586-94. doi: 10.1523/JNEUROSCI.1868-09.2009
62. Raichle EM, MacLeod AM, Snyder AZ, Powers WJ, Gusnard DA, Shulman GL. A default mode of brain function. Proc Natl Acad Sci USA. (2001) 98:676-82. doi: 10.1073/pnas.98.2.676

63. Greicius MD, Krasnow B, Reiss AL, Menon V. Functional connectivity in the resting brain: a network analysis of the default mode hypothesis. Proc Natl Acad Sci USA. (2003) 100:253-8. doi: 10.1073/pnas.01350 58100

64. Buckner RL, Krienen FM, Castellanos A, Diaz JC, Yeo BT. The organization of the human cerebellum estimated by intrinsic functional connectivity. $J$ Neurophysiol. (2011) 106:2322-45. doi: 10.1152/jn.00339.2011

65. Greicius MD, Srivastava G, Reiss AL, Menon V. Default-mode network activity distinguishes Alzheimer's disease from healthy aging: evidence from functional MRI. Proc Natl Acad Sci USA. (2004) 101:4637-42. doi: $10.1073 /$ pnas. 0308627101

66. Olivito G, Lupo M, Iacobacci C, Clausi S, Romano S, Masciullo M, et al. Structural cerebellar correlates of cognitive functions in spinocerebellar ataxia type 2. J Neurol. (2018) 265:597-606. doi: 10.1007/s00415-018-8738-6

67. Khan AJ, Nair A, Keown CL, Dakto MC, Lincoln AJ, Muller RA. Cerebro-cerebellar resting state functional connectivity in children and adolescents with autism spectrum disorder. Biol Psychiatry. (2015) 78:625-34. doi: 10.1016/j.biopsych.2015.03.024

68. Allen G, McColl R, Bernard H, Ringe WK, Fleckenstein J, Cullum CM. Magnetic Resonance Imaging of cerebellar-prefrontal and cerebellar parietal functional connectivity. Neuroimage. (2005) 28:39-48. doi: 10.1016/j.neuroimage.2005.06.013

69. Olivito G, Cercignani M, Lupo M, Iacobacci C, Clausi S, Romano S, et al. Neural substrates of motor and cognitive dysfunctions in SCA2 patients: a network based statistics analysis. Neuroimage Clin. (2017) 14:719-25. doi: 10.1016/j.nicl.2017.03.009

70. Middleton FA, Strick PL. Cerebellar output: motor and cognitive channels. Trends Cogn Sci. (1988) 2:348-54. doi: 10.1016/S1364-6613(98)0 $1220-0$

71. Groen WB, Buitelaar JK, van der Gaag RJ, Zwiers MP. Pervasive microstructural abnormalities in autism: a DTI study. J Psychiatry Neurosci. (2011) 36:32-40. doi: 10.1503/jpn.090100

72. Biswal BB, Van Kylen J, Hyde JS. Simultaneous assessment of flow and BOLD signals in resting-state functional connectivity maps. NMR Biomed. (1997) 10:165-70. doi: 10.1002/(SICI)1099-1492(199706/08)10:4/ $5<165::$ AID-NBM454>3.0.CO;2-7

73. Woo CW, Krishnan A, Wager TD. Cluster-extent based thresholding in fMRI analyses: pitfalls and recommendations. Neuroimage. (2014) 91:412-9. doi: $10.1016 /$ j.neuroimage.2013.12.058

Conflict of Interest: The authors declare that the research was conducted in the absence of any commercial or financial relationships that could be construed as a potential conflict of interest.

Copyright (๑) 2020 Lupo, Olivito, Clausi, Siciliano, Riso, Bozzali, Santorelli, Silvestri and Leggio. This is an open-access article distributed under the terms of the Creative Commons Attribution License (CC BY). The use, distribution or reproduction in other forums is permitted, provided the original author(s) and the copyright owner(s) are credited and that the original publication in this journal is cited, in accordance with accepted academic practice. No use, distribution or reproduction is permitted which does not comply with these terms. 